\title{
Conhecendo pessoas - uma ciência, uma arte: breve relato de uma experiência na graduação médica da EPM-Unifesp
}

\author{
Knowing people - a science, an art: \\ a brief description of the experience in the Undergraduate Medical from EPM-Unifesp \\ Conocer personas - una ciencia, un arte: \\ una breve descripción de la experiencia en el pregrado de medicina de la EPM-Unifesp
}

Um dos maiores desafios da formação numa Escola Médica é integrar o ensino da parte exata (aspectos físicos e objetivos) com o ensino dos aspectos subjetivos que envolvem o estudo da pessoa. Como fazer os alunos perceberem que ser um bom médico inclui ser sensível ao sofrimento do outro? Como ensiná-los a valorizar a qualidade da comunicação e dos vínculos com o paciente? E como fazê-los perceber que estas qualidades não são acessórias, mas fundamentais para o desempenho e eficácia da tarefa médica? Finalmente, como ajudá-los a desenvolver atitudes e habilidades necessárias para a formação deste profissional?

No primeiro ano da graduação em Medicina da Universidade Federal de São Paulo, como introdução a um programa que se estende por todo o curso, a disciplina de Psicologia Médica utiliza as contribuições das ciências e das artes para ampliar o conhecimento do aluno em relação às pessoas e aos dilemas humanos. Materiais pedagógicos, textos científicos, contos literários e filmes são estímulos para debates, discussões e planejamento de trabalhos (De Marco et al., 2009).

A intenção é aguçar a auto-observação e a observação das pessoas; instrumentalizá-las para que tenham a flexibilidade necessária para enfrentar as situações, examinando e considerando os aspectos relevantes presentes no campo relacional e comunicacional (o que inclui o reconhecimento de seus estados e sentimentos, bem como os de seus pacientes). Nas discussões, procuramos instrumentalizá-los para reconhecerem e evoluírem suas capacidades de observação, empatia e continência. Para que esta instrumentalização seja efetiva, é nossa intenção que o curso tenha forte cunho experiencial. Contribui para essa finalidade a discussão das vivências despertadas, bem como a própria relação professor-aluno, que pretendemos que sirva de modelo de uma relação viva e autêntica.

"Conhecer pessoas" é o mote do curso que pretende (re)aproximar os alunos das diferentes áreas que historicamente têm se interessado pelo conhecimento e equacionamento dos dilemas humanos. As aulas, em pequenos grupos (vinte alunos), destinam-se a facilitar o contato entre professores e alunos e favorecer ampla participação.

Por meio da discussão das contribuições das diferentes áreas de conhecimento - como mitologia, filosofia, psicologia, sociologia, antropologia, história -_bem como de produções ligadas à arte (como literatura, teatro e cinema), procuramos sensibilizar os alunos para o imenso manancial que estas áreas têm produzido para o conhecimento das pessoas, seus conflitos e dilemas.

Por exemplo, por intermédio da abordagem da psicologia, acessar conhecimentos do desenvolvimento da personalidade, seus momentos críticos, progressões e regressões, demonstrando a ajuda que estes conhecimentos podem proporcionar na detecção de fatores e situações de risco que contribuem para a saúde e a doença, bem como as reações da pessoa frente ao adoecer.

Estes mesmos conhecimentos podem ser muito enriquecidos por meio de contato com manifestações ligadas à arte.

Buscar, nas humanidades e nas artes, uma forma de conhecimento fundamental para a 
prática médica, já era apontado por Gregório Marañón (Gallian, 2002) ao elencar o que ele definiu como as cinco fontes do saber médico. Segundo o grande endocrinologista e escritor espanhol, a literatura, a arte e a experiência extramédica da vida têm uma importância tão grande quanto as fontes cientificas, na medida em que é na fonte das humanidades onde o clínico encontra algo de fundamental para o bom exercício da prática médica: intuições sobre a vida humana.

Pesquisadores brasileiros (Barros, 2011) acabam de relatar que um dos maiores escritores brasileiros do século 19, Machado de Assis, foi o primeiro a descrever um estranho distúrbio psiquiátrico, a "folie à deux". A narrativa de Machado, no conto O Anjo Rafael [1869], combina todos os elementos que seriam descritos por Lasegue e Falret, os descobridores "científicos" da "folie à deux", em 1887, oito anos depois da publicação do conto de Machado. Este conto ilustra como a literatura pode contribuir para o conhecimento da Psiquiatria, oferecendo uma descrição detalhada das condições psicológicas das personagens.

Assim, se queremos um retrato vivo de como se sente e o que se passa com um doente e seu entorno, a leitura de "A morte de Ivan Illitch" pode ser muito enriquecedora. No texto de psicologia, vamos encontrar mais informação conceitual, na literatura (nos bons escritores) encontraremos mais a "vida como ela é":

O clínico dizia: isto e aquilo indicam que o senhor tem isto ou aquilo; mas se o exame não confirmar que o senhor tem isto ou aquilo, devemos levantar a hipótese de ter isto ou aquilo... Ivan Ilitch só se preocupava com uma coisa: o que tinha era grave ou não? O doutor, porém, não ligava para a descabida pergunta. Do seu ponto de vista, o capital era decidir entre um rim flutuante, uma bronquite crônica ou uma afecção do ceco. Não estava em pauta a vida de Ivan Ilitch, mas sim decidir pelo rim ou pelo ceco. E o facultativo, brilhantemente resolveu, segundo pareceu a Ivan llitch, a favor do ceco... Exatamente o que Ivan Ilitch fizera mil vezes, e com o mesmo brilhantismo, em relação a um acusado. (Tolstoi, 1998, p.37)

Se quisermos conhecer mais sobre o médico, sua personalidade e as vicissitudes do exercício da medicina, podemos estudar uma série de textos (psicológicos, sociológicos, antropológicos), mas se, complementarmente, fizermos uma reflexão sobre o mito de Asclépio e seu tutor Chiron (o curador-ferido), com certeza sairemos bastante enriquecidos.

Por outro lado, se desejamos saber como se sente um médico quando adoece, estes trechos são uma amostra de quão instigante é o livro "O médico doente" de Dráuzio Varela:

Basta cair doente para que todos se
considerem no direito de dar
ordens: Já para a cama; Não saia
no sereno; Vista o agasalho.
O mais humilhante é obedecer com
a docilidade dos cordeiros, porque
a doença tem o dom de nos fazer
regredir ao tempo em que nos
entregávamos indefesos aos
cuidados maternos. Na cadeia, vi
muito assaltante de renome clamar
pela mamãezinha na hora da dor.
(Varela, 2007, p.19)

Durante o curso, assistimos e discutimos dois filmes: Freud Além da Alma e Os Quatro Diamantes.

O primeiro desperta muito interesse dos alunos pela postura investigativa do médico recém-formado Sigmund Freud na busca de entendimento dos quadros histéricos. O filme serve como ilustração para discutir com os alunos noções básicas de Psicanálise e sua contribuição para o conhecimento das pessoas.

O segundo filme, Os Quatro Diamantes, baseado numa história real (dirigido por Peter Werner, 1995), mostra a luta de um menino e sua família com uma doença grave (câncer). $O$ menino Christopher, que costuma fantasiar ser cavaleiro da Távola Redonda, em função da descoberta de um câncer, é obrigado a fazer quimioterapia durante suas férias escolares. Ao retornar às aulas, ao invés da tradicional redação "o que fiz nas férias de verão", é liberado pelo 
professor para escrever uma história de ficção. Envolvendo, em suas fantasias de cavaleiro, médicos e familiares, aborda a luta que trava com sua doença. Este filme sensibiliza muito os alunos, promovendo ampla discussão sobre a comunicação da médica com seu paciente e as diversas reações ao adoecer.

Na literatura, um dos textos que temos utilizado é o conto "O Espelho" (1882) de Machado de Assis (Brayner, 1981), autor conhecido pelo olhar minucioso sobre o comportamento humano. Neste conto, o personagem, ao receber um posto militar, é surpreendido pelo respeito e destaque que recebe quando está fardado. Ser visto fardado torna-se necessidade, a ponto de não conseguir ver seu reflexo no espelho quando fica sozinho por um breve período. O uniforme militar serve como metáfora para se discutir o uso do avental branco, sua interferência nos relacionamentos e o respeito a ele conferido. Numa avaliação do curso, este conto foi apontado pela maioria dos alunos como o momento mais marcante, pelo fato de ajudá-los a refletir sobre o papel que ocupam e as vivências despertadas quando em contato com os pacientes. Perceber, desde a entrada no curso médico, a responsabilidade e o poder que os pacientes Ihes conferem mobiliza emoções intensas. Numa das classes, ao discutir o conto, um aluno comentou sobre o "poder" que sentia ao vestir seu avental:

"Num dia em que fomos observar o trabalho numa Unidade Básica de Saúde, eu estava chegando - já de avental - e dois pacientes brigavam na porta para ver quem entrava primeiro. Ao me verem, pararam de brigar e abriram espaço para que eu passasse. Assim que eu passei, voltaram a discutir".

O relato deste aluno trazia o espanto de se deparar com tanto poder para "abrir seu caminho", mostrando, ao mesmo tempo, sua satisfação com todo o respeito que lhe era dirigido.

Assim como este fato relatado, os anos de graduação médica despertam inúmeras vivências intensas, que necessitam espaços de discussão, suporte e elaboração. As aulas de Psicologia Médica favorecem que estas vivências sejam ventiladas e o tema "conhecer pessoas" abordado durante todo o semestre, de diversas maneiras: os alunos observam os outros, a si próprios e aos pacientes. Isto foi apontado por diversos alunos em suas avaliações:
"A habilidade que mais desenvolvi foi a de observar a mim mesma e refletir mais sobre isso".
"Ao longo do curso descobri muito sobre mim mesmo e isso foi algo que me assustou. Percebi que Psicologia Médica é muito importante e deve ser trabalhada durante toda a vida".

Outra atividade marcante é o trabalho final, cujo tema é "Conhecendo pessoas: uma ciência, uma arte". O trabalho é proposto já no início do curso, e os alunos se dividem em grupos (de seis a sete alunos), com a tarefa de elaborarem, focados no tema, uma apresentação para o resto da turma. Eles são estimulados a utilizar recursos tanto da ciência como da arte na formatação do trabalho. A forma e apresentação são muito variadas: montagem de cenas de teatro, produção de filmes, entrevistas etc. A experiência promove a aproximação a um campo de conhecimento a partir de uma abordagem pouco habitual para um estudante de medicina, envolvendo um importante componente lúdico. Também proporciona oportunidade de exercitar o trabalho em grupo e conhecer melhor seus colegas e a si mesmo.

Estes trechos fornecem uma noção das repercussões do trabalho final:

“Vejo que através de tudo o que passamos durante o processo de construção do trabalho final, aprendi um pouco mais o que é ser médico. Ser médico é muito mais do que aprender técnicas, é uma arte de conhecer o outro [...] E essa arte não se aprende de uma só vez, mas continuamente, num processo eterno, porque não só uma pessoa é diferente da outra como o mesmo paciente que conhecemos hoje pode ser outro amanhã. Estamos em constante mudança." 
"Gostei muito de ter feito o trabalho final do curso. Revi e acrescentei conhecimento numa área que, repito, acredito ser de extrema importância na subjetividade médica. Pude relembrar diversos aspectos colocados em sala durante o curso e, assim, começar a finalizar a primeira de muitas etapas em meu aprendizado de psicologia médica."

O curso de Psicologia Médica da Universidade Federal de São Paulo tem confirmado o enorme potencial que a utilização conjunta de recursos das ciências e das artes tem na instrumentalização do futuro profissional para uma aproximação mais integral e eficiente ao seu campo de atuação. $\mathrm{O}$ formato deste curso tem sido estimulante para alunos e professores.

Tomamos emprestadas as palavras dos próprios alunos, para ilustrar a contribuição do curso em

\section{Colaboradores}

Os autores trabalharam juntos em todas as etapas de produção do manuscrito. instrumentalizá-los e estimulá-los a "conhecer pessoas":

"Há muitas coisas e sentimentos atrás dos atos, atitudes e da própria identidade das pessoas."

"Conhecer pessoas é um desafio maior do que imaginávamos e um aprimoramento interminável."

Mario Alfredo De Marco Departamento de Psiquiatria, Escola Paulista de Medicina, Universidade Federal de São Paulo (EPM Unifesp). Rua Borges Lagoa, 570, $1^{\circ}$ andar. Vila Clementino, São Paulo, SP, Brasil. 04.038-020. mariodemarco@globo.com Mariella Vargas Degiovani Departamento de Psiquiatria, EPM/Unifesp. Dante Marcello Claramonte Gallian Centro de História e Filosofia das Ciências da Saúde, EPM/Unifesp Ana Cecília Lucchese Departamento de Psiquiatria, EPM/Unifesp.

\section{Referências}

BARROS, D.M.; BUSATTO FILHO, G. First fictional report of folie à deux. Brit. J. Psychiatr., v.198, n.1, p.30, 2011. Doi: 10.1192/bjp.198.1.30

BRAYNER, S. (Org.) O conto de Machado de Assis: antologia. Rio de Janeiro: Civilização Brasileira, 1981.

DE MARCO, M.A. et al. Semiologia Integrada- uma experiência de aproximação antecipada e integrada à prática médica. Rev. Bras. Educ. Med., v.33, n.2, p.282-90, 2009.

GALLIAN, D.M.C. As humanidades e o saber médico. Notandum, v.5, n.9, p.47-50, 2002.

TOLSTOI, L. A morte de Ivan Ilitch. São Paulo: Publifolha, 1998.

VARELLA, D. O médico doente. São Paulo: Companhia das Letras, 2007. 